\title{
INSPECTION OF FOOD AT OUR PORTS.*
}

By J. WRIGHT MASON, M.B., C.M., D.P.H., M.R.C.S.E., Medical Officer of Health, City and Port of Kingston-upon-Hull.

$\mathrm{T}^{\mathrm{H}}$ HERE is no universal method for examining imported cargoes of food stuffs, only some two Authorities having powers vested in them for this purpose. By an Order of the Local Government Board issued in 1892, certain sections of the Public Health (London) Act, 1891, were made applicable to the Port of London, and further powers were obtained in 1898 . Under these powers the examination of food stuffs in London is conducted by the Port of London Sanitary Authority immediately on arrival and before being deposited or exposed for sale. By a recent Order (1906) obtained by the Manchester Port Sanitary Authority, similar powers have been conferred. At our other ports food stuffs are only examined after being landed and deposited or exposed for sale, as at present we possess no powers to interfere at an earlier stage, and the duties are then carried out by the Local Sanitary Authority.

The Bill recently introduced into Parliament by the President of the Local Government Board provides as follows :-

"The power of making regulations under the Public Health Act, 1896, and the enactments mentioned in that Act, shall include the power of making regulations authorising measures to be taken for the prevention of danger arising to public health from the importation, preparation, storage, and distribution of articles of food or drink (other than drugs or water) intended for human consumption, and without prejudice to the generality of the powers so conferred."

This Bill, if passed into law, will no doubt confer a necessary and long-desired power upon Port Sanitary Authorities, as under existing arrangements large consignments of food arrive and are despatched to various centres throughout the country without any inspection whatever taking place, thus leaving it open for inferior, innutritious, and often unwholesome food, to be improperly distributed.

An inspection before being landed or before leaving the docks would not only be beneficial from a public health point of view, but would also be some guarantee to the consignee, retailer, and the public generally, that they are being more fully protected.

* Paper read before the. Incorporated Society of Medical Officers of Health, on April 12th, 1907. 
As H.M. Customs enforce the powers vested in them for excise and other purposes, including the taking of samples of butter and margarine for analysis, so should Port Sanitary Authorities be empowered to board vessels and examine food stuffs before they are allowed to be distributed.

According to the Board of Trade returns, the total value of imported foods arriving at thirteen of the principal ports in this country in 1905

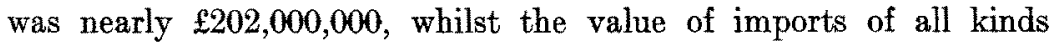
amounted to some $£ 484,000,000$. It will, therefore, be seen that nearly half the value of imports refers to food. During the last quinquennial period, the total imports at the thirteen ports alluded to shows an increase of $£ 33,000,000$ over those for 1901, and $£ 25,000,000$ of this increase is credited to food stuffs. Our principal supplies come from the United States, Russia, Canada, British India, Denmark, Australia and New Zealand, Germany, Netherlands, France, and Belgium.

As an illustration of the importance and necessity for inspection by Port Sanitary Authorities, I would mention the importation of very young calves from Holland and elsewhere. These arrive in large numbers weekly, especially during the months of February, March, April, and May. Some are immature, but being consigned inland, they escape inspection at the port of entry. At Hull at one time it was customary to notify the medical officers of health of the districts to which these carcasses were consigned, with the result that they were shipped by another route. If, however, the powers possessed by the ports of London and Manchester were extended to all ports, this evasion could not be resorted to.

Very large quantities of frozen meat are now imported into this country. Frozen carcasses of sheep and lamb were first sent from Australia in 1880, from New Zealand in 1882, and from the Argentine in 1883. New Zealand now sends yearly to this country four million carcasses, and the River Plate region three million carcasses.

Some consignments of food may be old, damaged, or otherwise of a questionable character, and in the case of tinned goods the tins may have become blown or bulged.

The inspection advocated would prevent articles of a doubtful character when landed being distributed, which if once allowed to come into the hands of some dealers could be so manipulated and treated as practically to prevent anyone knowing they were unsound.

The power to inspect a ship's cargo consisting of food stuffs before or when being landed would enable an inspector to satisfy himself whether the cargo had been stowed in a proper manner so as to avoid 
damage to the same, also whether injury had arisen to such food stuffs by being stowed with other cargo not intended for food, thereby rendering all or some probably unfit for human consumption. The continual supervision of articles landed at the docks and quays within a port would also enable an Authority to intercept goods damaged subsequent to their being landed.

Regulations requiring that meat intended for export should bear a label indicating that it has been subjected to official inspection are in force in Holland, Denmark, New Zealand, and Belgium, and in June, 1906, the United States Government passed similar regulations providing for a thorough inspection and marking of all food stuffs before being exported. These are important regulations, and should do much to give confidence to the public that efforts are being made to ensure a purer and better food supply. Nevertheless, it is allimportant that a thorough and efficient inspection by qualified officers should be made of all foods arriving at our ports.

The American regulations also provide that no meat food products intended for foreign commerce shall contain any substance which lessens its wholesomeness, nor any drug, chemical, or dye or preservative other than common salt, sugar, wood smoke, vinegar, pure spices, and, pending further inquiries, saltpetre.

Inspection and sampling of prepared meats and meat food products by Department employes shall be conducted in such a manner and at such times as may be necessary to secure a rigid enforcement of this regulation. It is, however, provided that in accordance with the direction of the foreign purchaser or his agent, meats and meat food products prepared for export may contain preservatives in proportions which do not conflict with the laws of the foreign country to which they are to be exported. When such meats or meat food products are prepared for export under this regulation they must be prepared in compartments of the establishment separate and apart from those in which meats and meat food products are prepared according to the regulations, and such products must be kept separate and be labelled with special trade labels, approved by the Secretary of Agriculture, and indicating that such products are for export only. Special export certificates will be issued for meats and meat food products of this character, and, if the products are not exported, under no circumstances will they be allowed to enter domestic trade.

In my opinion, any future regulations should require that all imported tinned foods should bear the name and address of the manufacturer, and also the date when packed.

In 1905 the following food stuffs were seized and condemned by 
the Port of London Sanitary Authority : 3,517 quarters and 1,463 pieces of beef ; 15,070 carcasses and 784 pieces of mutton; 437 cases of veal, pork, etc.; 524 crates of rabbits; five cases and 1,121 tins of canned meat, and 1,666,860 eggs. To these may be added large quantities of fruit, jam, marmalade, cocoa, tea, coffee, nuts, etc., etc. This illustrates the necessity and advantages of powers of inspection being vested in Port Sanitary Authorities. It would have been interesting to show the results of such an examination at other ports had the Authorities been empowered to make a similar inspection.

The inspection should be carried out without undue delay and interference with commerce, and should be conducted in conjunction with the Customs inspection. The inspector or inspectors appointed to carry out the work should be competent men and possess the special certificate for the examination in meat and other foods granted by the Royal Sanitary Institute, and they should act directly under the direction and supervision of the medical officer of health.

The Authorities of many of our large cities and ports recognize the necessity of attaching a veterinary surgeon to their foods inspection department, as, from their knowledge and training, he is the better qualified to undertake this work. It would be advantageous to have such a qualified person attached to the Port Sanitary Staff.

It is also important where large cargoes of food of a doubtful and perishable character have to be dealt with, that suitable warehouse accommodation should be provided for the purpose of examining and sorting the same, and in order that there may be no unnecessary delay caused in the discharge of a ship's cargo. The goods which are passed after being sorted should bear an official label or stamp certifying that they have been examined.

An inspection of this kind, I may say, is at present carried out at Hull by the Local Sanitary Authority, but only in respect of perishable fruit cargoes, and then not until being landed and deposited for sale. On the arrival of such cargoes, some of which may be in a faulty or unsatisfactory condition, notice is given to the auctioneer that the goods may be sold only subject to being conveyed to a warehouse provided by the Corporation, and the good separated from the bad under official inspection before the former is allowed to be retailed to the public. This inspection, however, does not include tinned meats and the many other imported meats and foods, which arrive in large quantities.

As a further argument in support of the inspection of food before being landed or leaving the docks, I would mention that in Hull on the auctioneers' bills of sale the following condition appears :- 
"If any of the contents of any package are spoilt, damaged, unsound, or otherwise defective, so as to be unfit for human consumption, such defective goods are not intended by the brokers or purchased by the buyers for the food of man, and buyers shall separate such defective goods from the bulk, and shall not use or sell any such for the food of man."

This clause has been held in law to free the wholesale dealer from liability, but the small dealer found selling the goods which he has purchased, often in an unwholesome condition, is liable to prosecution.

On inspection at the port of entry, all carcasses that have been stripped, and tinned goods or pieces of boned meat contained in packages, if of a suspicious or doubtful character, should be seized and condemned.

Whilst strongly advocating the provisions of the Public Health Acts and Food and Drugs Acts being extended to Port Sanitary Authorities with regard to the inspection of food supplies, it should not in any way relieve Local Sanitary Authorities from their duty and responsibility, and their efforts in this direction should not in any way be relaxed. Owing to their geographical position, ports of entry should be regarded as the first line of defence for the proper inspection of our food supplies before they are allowed to be distributed to our great commercial and industrial centres. Upon the Authorities of such ports should devolve the responsibility to arrest, if possible, not only the importation of infectious disease, but also that which has a far reaching effect upon the country generally, namely, our food supplies, upon which the populaíion is so much dependent, and whose health and welfare is the strength of our Nation and Empire.

\section{DISCUSSION.}

The President said they must all agree that the point of view which Dr. Mason had raised was one of considerable importance, and that if adequate inspection of food at the ports of entry could be obtained it was very desirable. The first point--that any such inspection must be uniform at all the possible ports of entry-was a very important one. At present it was very probable that any one particular port using certain powers would find that importers would divert their supplies to a port where less stringent regulations were enforced. It certainly seemed curious to him that only two ports, London and Manchester, had special powers for dealing with food. Personally he was of opinion that it would be an excellent thing if uniform powers were given to all port authorities where food could possibly enter into the country. They must not forget, however, that if such powers were given it would involve certain expenditure 
by the local port authorities. First there would be the necessary expenditure for warehousing, and secondly it was worthless having powers unless an adequate staff was provided for carrying out the inspection.

Dr. E. W. Hope (Liverpool) said there could be no two opinions as to the desirability of possessing powers for the inspection of food stuffs at the ports of entry. The advantages were obvious-so obvious, in fact, as almost to run the risk, one might say, of being over-estimated. Such examination would not in any degree absolve local sanitary authorities from any of the obligations which rested upon them. It was quite plain that certain food stuffs, fruit for example, might with great advantage be subjected to a preliminary sorting. The practice in Liverpool-and he believed it was a fairly widespread practice amongst the fruit traderswas to have a preliminary sampling of cases, and on that preliminary sampling the various cases of fruit were classified. Some of them were assumed to contain 50 per cent of damaged or useless fruit, oranges for instance, and others more or less. In that way the cases appeared upon the auctioneers' bills or catalogues, and they were sold with the knowledge that a certain proportion must be given over for destruction. They were purchased with that knowledge, and when they were purchased a further sorting took place. He had listened to what Dr. Mason had said as to whether the sorting should take place before the sale or after it. Personally he did not think it was of very much consequence, but he did think it was desirable that the sorting, whether before or after sale, should take place on some part of the Port Sanitary Authority's area, or somewhere within the jurisdiction of that authority. That, he thought, was much better than sending the fruit to the wholesale markets and having the sorting taking place there. In the Port Sanitary Authority's area there was greater privacy. There would be fewer trespassers and fewer children hunting around for damaged fruit. Therefore the risk of tainted fruit being eaten by children and people would be very much lessened. Another point referred to was the need for dispatch. Delay would be extremely harmful in the case of perishable goods such as fruit. With regard to the question of labelling cases to show that the fruit had been inspected, he saw no harm in it, but he was bound to say he saw very little good. With such a perishable thing as fruit the fact of its being labelled might lead local sanitary authorities to think they need not be so particular, because it had already been passed by the Port Sanitary Authority. That might be a very wrong impression. The fact of labelling would show that the inspectors of the port sanitary authorities had done their part of the business, but cases had been known in which food-stuffs had been labelled and stamped or dispatched from abroad, which nevertheless on arrival had been seized and condemned. Although it was a very good thing to have that first line of defence, it must be remembered that it was merely a first line, and nothing must be done to throw local sanitary authorities off their guard. Of course some expenses would necessarily be incurred, but, after all, that was a necessary incident of a port. If they wished to attract traders they would have to incur expenses in the same way in which a seaside resort incurred expenses in advertising its attractions. But the question had vexed all Port Sanitary Authorities for a 
very long time. Some had become weary of waiting and had obtained special powers of their own. The best way of meeting the difficulty which had come to his notice was the Bill introduced by Mr. Burns. It seemed to him to be one of the most ingenious ways of evercoming a very great difficulty that could possibly be devised. The principle of it was based upon the Act of 1896, which dealt with the importation of disease. It was an Act which brought into play all existing legislation designed with a view to check the importation of infectious disease, and would bring into play all existing legislation relating to the inspection and examination of food. He was very disappointed that the Bill did not proceed in the last Session, but he hoped it would go through at no distant date. In conclusion he expressed entire appreciation of the views put forward by Dr. Mason, and he hoped that all Port Sanitary Authorities would at an early date have the power which they desired.

Dr. R. M. Craven (Westmoreland) thought that if food was going to be examined, such examination would have to take place in a warehouse. Every railway company dispatched an invoice with goods sent to the station of delivery. That invoice stated to whom those goods were to be delivered. He did not see why they could not notify the medical officers of health of such consignments, and let them know what time the goods would arrive at the station consigned to.

DR. G. B. MrLlson (Southwark), dealing with the work at the Port of London, said that of course some cargoes arrived which without examination were palpably damaged. Those were sent off to the dock or warehouse and sorted there. With regard to fruit it would be impossible for it to be sorted before it arrived at the market. The quantities which arrived were so enormous that the great thing was to get the stuff into market and sold. If there was any question about its being good or bad, it was sold to be sorted. He had always held that they ought to have a warehouse where it could be sorted. At present the buyer took the stuff away, and they did not know whether or not it went for human consumption. The great difficulty was the immense volume of the stuff they had to deal with. With regard to meat it was very rarely there was a bad carcass, and only when there was a breakdown in the freezing machine. He had not observed any desire to pass such meat for human consumption. It was a great thing to have plenty of inspectors to wait for the stuff when it was landed and to examine it, and it must be dealt with in the warehouses. At the present time they were under the difficulty of having no power of entry to warehouses, although wharfingers had given them every facility, and had destroyed stuff which ought not to be sold. But lying behind, there was the feeling that there were certain wharfingers-he knew one or two-who dealt in unwholesome food. They bought such food-food which had deteriorated in its nature after it had come, say from Africa. Two or three years ago, unfortunately, he was led to allow some to go away for chicken food. He had no doubt it went for potted food or something of that kind. What they wanted were regulations, giving the power of entry into warehouses, and the power of sampling within a reasonable measure. Above all, authorities should be made alive to the necessity of employing an adequate staff at the business.

DR. R. M. CRaven pointed out that whilst a medical officer of health might take very good care that no diseased meat was allowed to be eaten in his district, yet a railway might run through the district which might convey such stuff to other districts.

Dr. BurLer (Willesden) said that port medical officers might tell them that inspectors at ports of entry were possible and desirable, and they 
would all agree that that was so. At a port of entry there was much inspectorial work to be done which would in a large measure protect their food supplies, but it was quite obvious that the practical considerations would limit that inspection, so that it would not be pọssible to prevent unsound food coming in, in spite of any such system of inspection as might be organized at the ports. Dr. Craven had suggested a system of notification to the local medical officers of health, and it would be desirable if practicable. The inspection of food in the retail shops-which was all local medical officers of health could do-was certainly inadequate, and it was desirable that the food supplies should be inspected in bulk. They had endeavoured to secure a system of food inspection by which carcasses should be inspected at the place where they were slaughtered. Central abattoirs had been advocated, where all animals should be slaughtered, and inspection made at such points. To have anything like a system that should be comprehensive it seemed desirable that in addition to the methods suggested by Dr. Mason, they should also have what Dr. Craven suggested, namely, notification to the local medical officers of health. That it would be costly there could be no doubt. Furthermore, it would be to the interest of any port authority not to have a too rigid inspection and not to have too many rejections. Such a port would obtain a reputation amongst shippers, who would go to a port whose regulations were not so severely enforced. It was really a question of national importance, and the gain would be to the people of the country to whom the food was consigned. Therefore he thought the expenses should come out of the Imperial exchequer. The port medical officer should be the man to carry out the work, but as the question was a national and not a local one, the cost should be borne by the nation itself.

DR. J. WRIGHT Mason in replying to the discussion thanked the various speakers for their criticisms. All ports, he said, were exceedingly anxious for local self-government; and desired the power of inspection, not only as a first line of defence, but knowing the dangers attending importation of food. The food supply, like infectious disease, should be dealt with at the port of its entry. On the question of sorting, and whether it should take place before or after the auction, he thought it should be after. Notice should be given and the food should be sold subject to inspection. It was only now and again that they were called upon to deal with enormous quantities, and they were dealt with as the emergency occurred. If they got proper regulations then he thought the first thing they ought to do was to follow the lines of experience. For instance, when they saw articles of a suspicious character, the ship should not be detained or the discharge of the cargo delayed, but the goods should be detained for inspection. He thought that if the Port Sanitary Authority undertook the first inspection, they should take the entire responsibility. There should be no such thing as giving a certificate; it should simply be said in the case of a good cargo that it had been examined. The question resolved itself into one great problem. They did not assume that they should inspect the food for the country, but as they received the disease of the country so they received the food; and he thought that in their various ports their staffs should have the inspection of all food supplies arriving in the country. 